RUNNING HEAD: Identity Concealment \& Exposure to Prejudice

\title{
Does Concealing a Sexual Minority Identity Prevent Exposure to Prejudice?
}

Jin X. Goh, Daniel N. Kort, Avery M. Thurston, Lina R. Benson, \& Cheryl R. Kaiser University of Washington

***This manuscript has been accepted for publication at Social Psychological and Personality Science. The final typesetting may differ from this version. $* * *$

\section{Please cite as:}

Goh, J. X., Kort, D. N., Thurston, A. M., Benson, L. R., \& Kaiser, C. R. (in press). Does concealing a sexual minority identity prevent exposure to prejudice? Social Psychological and Personality Science.

\section{Corresponding Author:}

Jin X. Goh

Department of Psychology, University of Washington

Email: jin.x.goh@gmail.com 


\section{Acknowledgment}

We would like to acknowledge all the sexual minority research assistants who worked on the video coding in Study 2. We would also like to thank Dr. James Rae, Dr. Kristina Olson, and the University of Washington Center for Statistics and the Social Sciences for their assistance with data analyses.

\section{Author Biographies}

Jin X. Goh is a postdoctoral researcher at the University of Washington, Seattle, WA, USA.

Daniel N. Kort received his Master of Science in psychology at the University of Washington.

Avery M. Thurston was a research assistant at the University of Washington.

Lina R. Benson was a research assistant at the University of Washington.

Cheryl R. Kaiser is professor and chair of Department of Psychology at the University of Washington. 


\begin{abstract}
Concealing a stigmatized identity is considered self-protective in that it presumably decreases exposure to bias during intergroup interactions relative to disclosing the identity. We conducted two studies exploring sexual minorities' expectations about the self-protective properties of concealment and the reality concerning whether concealment prevents exposure to bias. In Study 1, half of sexual minorities who imagined interacting with a straight peer chose to conceal their identity, and this was predicted by the belief that concealment carries protective benefits. Study 2 randomly assigned sexual minorities to reveal or conceal their sexual orientations in actual interactions with straight peers. Neither sexual minority partners nor independent sexual minority coders perceived less bias among straight partners who interacted with sexual minorities concealing vs. disclosing their identities. This was confirmed with Bayesian inferences demonstrating more evidence for the null model than the alternative. We discuss the potential benefits and costs of disclosure.
\end{abstract}

Key words: Sexual minorities, sexual orientation, concealment, prejudice 


\section{Does Concealing a Sexual Minority Identity Prevent Exposure to Prejudice?}

Sexual minorities often conceal their sexual orientation from strangers, friends, and family members (Quinn \& Earnshaw, 2011; 2013). Concealment offers a sense of security in a world that devalues and discriminates against those with a known stigmatized identity. However, when social norms shift toward egalitarianism, which has rapidly unfolded with sexual minorityrelated attitudes (Tankard \& Paluck, 2017; Westgate, Riskind, \& Nosek, 2015), the expression of bias declines (Crandall, Eshleman, \& O’Brien, 2002). As such, concealment may not carry the self-protective benefits that it presumably offers. As concealment inflicts significant psychological burdens on the stigmatized (Pachankis, 2007), there is value in understanding the role of concealment in the prevention of discrimination.

\section{Concealable Stigmatized Identities during Intergroup Interactions}

Because of the legacy of anti-LGBTQ discrimination, sexual minorities enter intergroup interactions with fear of bias, including concerns about potential verbal or physical abuse (Conley, Devine, Rabow, \& Evett, 2003). This fear can trigger self-protective strategies aimed at shielding oneself against potential bias (Crocker, Major, \& Steele, 1998; Goffman, 1963; Miller \& Kaiser, 2001; Miller, Rothblum, Felicio, \& Brand, 1995). For sexual minorities, this often includes "passing" as a straight person by concealing their sexual orientations (Goffman, 1963; Griffith \& Hebl, 2002). Passing is motivated largely by the belief that it will prevent exposure to bias (Crocker et al., 1998; Goffman, 1963; Hebl, Foster, Mannix, \& Dovidio, 2002; Jones et al., 1984; Newheiser \& Barreto, 2014; Major \& Gramzow, 1999). Although sexual minorities perceive concealment to be beneficial, this self-protective strategy comes at a price as it places tremendous psychological, cognitive, and physical distress on them (Pachankis, 2007; Quinn \& 
Earnshaw, 2011). Furthermore, stigmatized individuals feel less authentic and belonging when they concealed their identities during intergroup interactions (Newheiser \& Barreto, 2014).

Despite the strong legacy of anti-LGBTQ bias, attitudes toward sexual minorities have undergone a rapid change in recent years. This is evidenced in the 2015 decision by the Supreme Court of the United States (SCOTUS) to legalize same-sex marriage. Institutional changes in laws herald further normative-driven attitude changes. After the SCOTUS ruling, Americans expressed more support for gay marriage than they did beforehand (Tankard \& Paluck, 2017). When egalitarian norms toward the LGBTQ community are strong, straight people increasingly regulate their behaviors to appear more egalitarian during interactions with sexual minorities (Crandall et al., 2002; Hebl et al., 2002; Plant \& Devine, 1998; Richeson \& Shelton, 2007). Sometimes members of non-stigmatized groups over-correct and behave even more positively toward stigmatized individuals than non-stigmatized people, particularly in the presence of others (Dasgupta \& Rivera, 2006; Mendes \& Koslov, 2013; Vorauer \& Turpie, 2004).

These norm-induced self-regulatory changes in behavior among straight people raise the possibility that there will be a mismatch with respect to sexual minorities' beliefs about whether concealment prevents exposure to bias and the reality that it does so, at least in egalitarian contexts. Concealment may even backfire as making a stigmatized identity salient could cue others to express behaviors consistent with egalitarian norms, and express more positive and accepting behavior toward the stigmatized relative to the non-stigmatized. These studies explore this misperception, and do so in a context that is highly egalitarian, a university context in a liberal American city.

\section{Current Research}


Two studies examined sexual minorities' beliefs about the self-protective properties of concealment and whether concealment prevents exposure to bias in actual interactions. Study 1 examined whether sexual minorities' belief that concealment is self-protective predicts decisions to conceal or reveal their stigmatized identity in an imagined interaction with a straight student at their university. This study serves to test whether an important potential barrier to confrontation (perceived self-protection) is relevant to the disclosure decisions of sexual minority students who reside in this same university context in Study 2.

Study 2 randomly assigned sexual minorities to reveal or conceal their sexual orientations in interactions with straight partners, and we explored biased behaviors expressed by straight partners. We tested three potential accounts for how concealment (vs. disclosure) affects straight partners' behaviors. First, evidence for the concealment as self-protection hypothesis (Crocker \& Major, 1989; Jones et al., 1984) would manifest in straight partners expressing less prejudiced behaviors when the sexual minority partner conceals vs. reveals their identity. Alternatively, the egalitarian norm hypothesis (Crandall et al., 2002; Plant \& Devine, 1998) would result in straight partners expressing no reduction in prejudiced behaviors toward sexual minorities who conceal versus reveal their identity as norms would sanction the expression of bias during interaction with a known sexual minority. A third possibility is the over-correction hypothesis (Mendes \& Koslov, 2013; Vorauer \& Turpie, 2004) whereby straight people would produce less biases toward sexual minorities who reveal their identity relative to those who conceal as straight participants may miscalibrate the effort needed to comply with egalitarian norms. Study 2 examined these three possible patterns of behavior toward sexual minorities in three manners: (1) straight participants' perceptions of their own prejudiced behaviors, (2) sexual minorities' perceptions of their straight partners' behavior, and (3) and independent sexual minority coders' 
perceptions of the straight partners' behavior. This tripartite approach allowed us to explore consistency around perceiver, target, and third-party perceptions.

Whereas scholarship in intergroup interactions typically focuses on the experiences of the stigmatized partner engaging in concealment (Major \& Gramzow, 1999; Smart \& Wegner, 1999), much less attention has focused on how concealment affects non-stigmatized interaction partners' prejudicial behavior. Our studies offer insight into this, with several methodological strengths. First, we examined actual behaviors within dyadic intergroup interactions between stigmatized and non-stigmatized group members (i.e., not confederates), and we focused on a stigmatized group that is underrepresented in research. Second, we measured perceived discriminations in Study 2 from three distinct sources (i.e., straight partners, sexual minority partners, and independent coders), allowing us to examine if discrimination lies within actual behaviors or from perceptual processes guided by social identities. Third, Study 2 randomly assigned sexual minorities to conceal or disclose their sexual orientations, a particularly strong and powerful manipulation for exploring our research questions.

\section{Study 1}

Study 1 examined whether beliefs about the self-protective benefits of concealment motivate sexual minorities to conceal their sexual orientation. This study serves to underscore the expectations about concealment that sexual minorities bring to their interactions with straight individuals. For data and materials in Studies 1 and 2, see: https://osf.io/evzkf/

\section{Method}

Participants. Ninety-four undergraduates (26 men; 60 women; 8 indicated gender nonconforming, transgender, or rather not say; $M_{\text {age }}=19.27$ ) from a large public university participated in an online study for course credit, with the goal of recruiting as many self- 
identified sexual minorities as possible within an academic quarter. Prior to starting the study, all participants were pre-screened and self-identified as sexual minorities. A subsequent demographic questionnaire at the end of the study gave the following breakdown: 32 participants self-identified as gay or lesbian, 56 as bisexual, and 6 would rather not say or indicated another sexual orientation that was not listed. One identified as straight at the end and was excluded.

Procedure. Participants were recruited for a study purportedly on their thoughts and feelings during political discussions. Participants imagined an interaction with a straight student about an issue on campus, in which the straight student did not know their sexual orientation. Specifically, participants imagined discussing the following issue: "LGBTQ leaders are lobbying the University of Washington administration for increased annual funding for LGBTQ groups. Some administrators and groups oppose the effort, contending that increasing their funding will strip other worthy organizations of funding." This ambiguous prompt provides the possibility for participants to imagine that motives to the decrease funding did not necessarily stem from bias against LGBTQ students.

Participants then indicated whether they would reveal their sexual orientation to their straight partners and answered questions about their beliefs on the protective benefits of concealment. We also explored participants' perceptions of straight students' propensity to express discrimination as a covariate. This provided insight into the unique relationship between self-protective presumptions and the decision to conceal or disclose, as self-protective beliefs likely covary with expectations about discrimination. Participants also wrote about their anticipated feelings during the interaction; these responses were not analyzed. 
Decision to reveal or conceal. Participants answered a Yes/ No question: "When having this discussion with the straight student, would you tell the person that you are LGBTQ?" Response was coded as $0=$ reveal and $1=$ conceal sexual orientation.

Beliefs about protective benefits of concealment. Three items assessed beliefs that concealment offers protection from becoming a target of discrimination. An example is: "In order to avoid being the target of anti-LGBTQ discrimination, it would be a good idea for me to hide my sexual orientation.” All questions used 7-point scales $(1=$ strongly disagree; $7=$ strongly agree; Cronbach's $\alpha=.84)$.

Potential perceived discrimination. Participants completed seven questions regarding potential perceived discrimination from the straight student during the imagined discussion. Examples include: "During this discussion, how likely is the straight student to express homophobia?" and "During this discussion, how likely is the straight student to be uncomfortable around LGBTQ people?” All questions used 7-point scales ( $1=$ extremely unlikely; 7 = extremely likely; $\alpha=.86$ ).

\section{Results}

For descriptive statistics and correlations, see Table 1. Of the 94 participants, 48 sexual minorities $(51.1 \%)$ indicated that they would not reveal their sexual orientations. We entered participants' beliefs about the protective benefits of concealment and their perception of potential discrimination simultaneously into a logistic regression model, with decision to conceal their sexual orientation as the dependent variable $(0=$ reveal; $1=$ conceal $)$. Participants' presumption that concealment is protective was a significant positive predictor of sexual minorities' decision to conceal their sexual orientation, $B=.65, S E=.20, p=.001, O R=1.92,95 \% \mathrm{CI}[1.30,2.86]$. 
Perceived potential discrimination did not predict decisions, $B=.05, S E=.24, p=.835, O R=$ $1.05,95 \%$ CI $[.66,1.67] .^{1}$

Table 1

Descriptive Statistics and Correlations of Measures in Study 1

\begin{tabular}{llll}
\hline Measures & $M(S D)$ & 1 & 2
\end{tabular}

1. Decision to Reveal or Conceal $\quad .51(0.50)$

2. Protective Benefits of Concealment $\quad 4.16(1.36) \quad .39 * * *$

3. Potential Perceived Discrimination $\quad 4.50(1.01) \quad .15 \quad .34 * * *$

Note. Decision to Reveal or Conceal was coded as $0=$ reveal sexual orientation; $1=$ conceal sexual orientation. Beliefs about the Protective Benefits of Concealment and Potential Perceived Discrimination both used 7-point scales. $* * * p<.001$.

\section{Discussions}

Sexual minorities in Study 1 came from a progressive university where the president is openly sexual minority, located in a liberal city (whose past two mayors have been open sexual minorities). Yet half of the participants still opted to conceal their sexual orientations in the imagined interactions. This speaks to the prevalence of concealment as a coping strategy among sexual minorities. Importantly, the decision to conceal was predicted by the presumption that

${ }^{1}$ Logistic regression with only presumed protective benefits of concealment predicting decision to conceal was significant (i.e., not controlling for perceived discrimination), $B=.67, S E=.19, p$ $=.001, O R=1.95,95 \%$ CI $[1.34,2.84]$. 
concealment could protect one from discrimination. This relationship remained even after controlling for perceptions of potential discrimination. Study 2 utilized dyadic interactions in the same campus environment to explore whether these expectations match straight individuals' behaviors toward fellow sexual minority students concealing or disclosing their identity.

\section{Study 2}

Study 1 found that sexual minorities perceive concealment as self-protective. Study 2 manipulated this protective strategy to examine whether sexual minorities were treated differently by straight people when they either concealed or revealed their sexual orientations. We assessed perceptions from three sources: straight interaction partners, sexual minority interaction partners, and independent coders.

\section{Method}

Participants. Seventy-seven pairs of same-gender, mixed-sexual orientation dyads participated, with the goal of recruiting approximately 80 dyads (40 dyads in each condition). Six dyad pairs were excluded because the straight partner failed the manipulation check (i.e., indicated partner's sexual orientation incorrectly) or the recruited sexual minority partner identified as straight at the end of the study. ${ }^{2}$ Of the remaining 71 pairs $\left(M_{\text {age }}=19.25\right), 31$ sexual minorities in the dyad were randomly assigned to disclose their sexual orientation and 40 were assigned to conceal their sexual orientation. All dyads were of the same gender (32 male and 39 female dyads). Of the 71 sexual minorities, 27 self-identified as gay or lesbian, 36 as bisexual,

${ }^{2}$ Recruited sexual minorities who did not disclose their sexual orientation at the beginning of the study (i.e., indicated they were straight) were dismissed and the session would end then. They were not included in the participant count above. 
and 8 indicated another sexual orientation that was not listed. The study was approved by the university’s Human Subjects Division.

Procedure. Participants were recruited based on their gender and sexual orientations, obtained from a battery of online prescreening surveys administered at the start of each term. Participants were contacted to participate in a study on political opinions and they were not aware that the study concerned sexual orientation. Each dyad was matched on gender and consisted of a self-identified straight student and a self-identified sexual minority student (i.e., self-identified as gay/lesbian, bisexual, or other non-straight sexual orientation).

The experimenter first led participants into separate rooms and informed them that they would be discussing political opinions with another student. Prior to meeting their interaction partner, participants were told they would exchange demographic information to learn about their partner. In the demographic form, all participants reported their age, gender, race, year in school, major, handedness, and sexual orientation. All sexual minority participants were informed that they would be randomly assigned to be represented by a fake profile to help control for variation in the impression formation process. For the concealment condition, their sexual orientation was altered to indicate that they were straight. For the disclosure condition, their handedness was instead switched. Thus, all sexual minority participants had a part of their identity switched, but only those in the conceal condition were presented as straight. To further decrease suspicion about the study's purpose, the researcher increased all the sexual minority participants' age and year in school by one year. The experimenter showed the sexual minority participants their altered demographic profile and instructed them that their interaction partner should not know their true identity or that their profile had been modified. The straight 
participants were not aware of any manipulation and none of their information was altered (i.e., all sexual minorities saw that their partners were straight).

After exchanging and learning one another's demographic information, participants were brought into the same room for a video recorded 5-min interaction. Participants chose an ostensibly "random" discussion topic from a jar, but all of the topics were the same prompt used in Study 1 regarding decreased funding for LGBTQ groups on campus. Afterwards, participants completed measures regarding their own and their partner's behaviors and attitudes and were debriefed. ${ }^{3}$

\section{Perceived Discrimination}

We measured three forms of perceived discrimination: 1. straight participants rated how biased they thought they personally behaved during the interactions; 2 . sexual minorities' perceptions of how their straight partners behaved; and 3. independent sexual minority-coders' perceptions of the straight participants' bias based on the videos of the recorded interactions.

Straight participants. Seven items measured straight participants' perception of their own biases during the interactions $(\alpha=.81)$. All items used 7-point scales $(1=$ strongly disagree; $7=$ strongly agree). Examples include "During the interaction, I was homophobic" and "During the interaction, I held stereotypical beliefs about LGBTQ people.”

Sexual minority participants. Seven items measured sexual minorities' perception of their straight partners' biases using the same items as straight participants' self-perception, with

\footnotetext{
${ }^{3}$ We collected additional measures that were not analyzed: Collective Self-Esteem, Rosenberg's Self-Esteem Scale, Internal and External Motivation to Respond without Prejudice, Positive and Negative Affect Schedule, and implicit anti-gay bias. Data are available on OSF.
} 
the exception that all first-person pronouns were switched to "My interaction partner" $(\alpha=.87)$. An example is "My interaction partner is homophobic." All items used the 7-point scales.

Sexual minority coders. Due to camera malfunction and clerical errors, videos from six dyads were lost, leaving videos of 65 dyads. All videos were thin-sliced to the beginning 2-min (Murphy et al., 2015). We recruited three trained coders who identified as LGBTQ because stigmatized people are more attuned to potential subtle biases than non-stigmatizers (Sommers \& Norton, 2006). The coders, blind to the experimental conditions and unaware of the participants' sexual orientations, rated their impressions of straight participants' behavior. Only the straight person was visible in the videos but coders could hear the interaction partner; they were told to code only the person visible in the videos. Coders rated the videos with the audio on using these four statements $(1=$ strongly disagree; 7 = strongly agree): "This person holds positive attitudes toward LGBTQ people” (reverse), “This person is uncomfortable around LGBTQ people”, “This person looks comfortable and engaged during the interaction" (reverse); and "This person looks friendly and warm during the interaction" (reverse). These four statements were averaged per coder and then averaged across coders, with good inter-rater reliability $(\alpha=.86)$. Thus, each straight participant received a coded perceived discrimination score, with higher scores indicating more negative impressions as judged by independent sexual minorities.

\section{Results}

Because all three dependent variables on perceived discrimination were measured only in one member of the dyad (i.e., no dependency), all analyses compared the concealment against the disclosure groups at the dyadic level using independent $t$-tests.

We complemented Frequentist analyses with Bayesian inferences using the JASP software with a default Cauchy prior width of 0.707 (JASP Team, 2018). We specifically used 
Bayes factor that compares a likelihood ratio of an alternative candidate model likelihood $\left(\mathrm{M}_{1}\right.$; the two groups are different) against the null model likelihood ( $\mathrm{M}_{0}$; the two groups are the same), expressed as $\mathrm{BF}_{10}$. Bayes factors can be interpreted as presenting evidence for the presence or absence of effects (Rouder, Speckman, Sun, Morey, \& Iverson, 2009). For instance, a BF $10=10$ indicates that the alternative model $\left(\mathrm{M}_{1}\right)$ is 10 times more probable than the null model $\left(\mathrm{M}_{0}\right)$; a $\mathrm{BF}_{10}=.10$ would suggests that the null $\mathrm{M}_{0}$ is 10 times more likely than the alternative $\mathrm{M}_{1}$. Under $\mathrm{BF}_{10}=1$, both null and alternative models are considered equally probable.

Overall descriptive statistics and correlations are displayed in Table 2. Descriptive statistics separated by conditions with frequentist statistical values are displayed in Table 3. Bayesian inference values are displayed in Table 4.

Table 2

Descriptive Statistics and Correlations of Measures in Study 2

\begin{tabular}{llcc}
\hline Measures & $M(S D)$ & 1 & 2 \\
\hline Straight's Self-Perceived Discrimination & $2.28(0.92)$ & \\
Sexual Minorities' Perceived Discrimination & $2.51(1.03)$ & $.24 *$ & $.37 * *$ \\
Sexual Minority Coders' Perceived Discrimination & $3.85(1.30)$ & $.49^{* * *}$ \\
\hline Note. All measures used 7-point scales. & & \\
$* p<.05 . * * p<.01 * * * p<.001$. & &
\end{tabular}


Table 3

Descriptive Statistics by Conditions and Frequentist Statistical Values in Study 2

\begin{tabular}{|c|c|c|c|c|c|c|}
\hline & Conceal & Reveal & & & & \\
\hline Measures & $M(S D)$ & $M(S D)$ & $t(d f)$ & $p$ & $d$ & $95 \% \mathrm{CI}$ \\
\hline Straight's Self-Perceived & 2.36 & 2.18 & 0.80 & .427 & 0.19 & {$[-0.27,0.62]$} \\
\hline Discrimination & $(0.85)$ & $(1.02)$ & (69) & & & \\
\hline Sexual Minorities' & 2.70 & 2.26 & 1.82 & .073 & 0.44 & {$[-0.04,0.93]$} \\
\hline Perceived Discrimination & $(0.97)$ & $(1.07)$ & (69) & & & \\
\hline Sexual Minority Coders' & 3.82 & 3.89 & 0.21 & .835 & 0.05 & {$[-0.73,0.59]$} \\
\hline Perceived Discrimination & $(1.27)$ & $(1.35)$ & $(63)$ & & & \\
\hline
\end{tabular}

Note. All measures used 7-point scales.

Table 4

Bayes Factors, Median Effect Size $\delta$, and 95\% Credible Interval in Study 2

\begin{tabular}{lcccc}
\hline Measures & $\mathrm{BF}_{10}$ & $\mathrm{BF}_{01}$ & Median $\delta$ & $95 \%$ CI \\
\hline Straight's Self-Perceived & 0.324 & 3.089 & -0.16 & {$[-0.62,0.27]$} \\
$\quad$ Discrimination & & & & \\
Sexual Minorities' Perceived & 1.005 & 0.995 & -0.38 & {$[-0.83,0.07]$} \\
$\quad$ Discrimination & & & & \\
Sexual Minority Coders' & 0.262 & 3.822 & 0.04 & {$[-0.40,0.50]$} \\
$\quad$ Perceived Discrimination & & & & \\
\hline
\end{tabular}


Straight participants' self-perceived discrimination. As shown in Table 3, straight participants whose sexual minority partners concealed their identity did not differ significantly from those with partners who revealed their identity. This is consistent with the egalitarian norm perspective that predicts that norms will prevent bias.

As shown in Table 4, Bayesian independent $t$-test revealed a $\mathrm{BF}_{10}=0.324\left(\mathrm{BF}_{01}=3.089\right)$, suggesting that the null $\mathrm{M}_{0}$ model (i.e., the two groups are the same) is 3 times more plausible than the alternative $M_{1}$ model (i.e., the two groups are different). This provides further support for the egalitarian norm hypothesis.

\section{Sexual minority participants' perception of straights' discrimination. Sexual} minorities who concealed their sexual orientation perceived marginally more discrimination in their straight interaction partners than those who disclosed their sexual orientation. This, too, is consistent with the egalitarian norm perspective. If anything, the trend is in the direction of the over-correction hypothesis with disclosure producing less perceived prejudiced behavior from straight partners relative to concealment.

Bayesian analysis suggests that both null and alternative models are equally probable, $\mathrm{BF}_{10}=1.005$.

Sexual minority coders' perception of straights' discrimination. Consistent with the egalitarian norm perspective, independent sexual minority coders did not perceive straight participants to behave differently across conditions. ${ }^{4}$

\footnotetext{
${ }^{4}$ Two separate sexual minority coders rated sexual minorities' behaviors to explore whether their behavior differed across the two conditions. The videos were coded (with audio) on positivity ( $\alpha$ $=.71)$, engagement $(\alpha=.75)$, and comfort $(\alpha=.42)$. Sexual minorities did not differ across the conditions, $p s>.41$, suggesting that the manipulation did not alter sexual minorities' observable behaviors toward their partners. See OSF for more details.
} 
Bayesian independent $t$-test supported this egalitarian norm perspective $\left(\mathrm{BF}_{01}=3.822\right)$, which suggests that the null $\mathrm{M}_{0}$ is approximately 4 times more likely than the alternative $\mathrm{M}_{1}$.

\section{Discussion}

Altogether, the three assessments of behavior do not support the concealment as selfprotective perspective. Both Frequentist and Bayesian analyses supported the perspective that social norms prevent the expression of bias and subsequently there will be no visible differences in how straight people treat sexual minorities who either revealed or concealed their sexual orientations. The only hint that supported the over-correction hypothesis was found in sexual minorities' reports (Table 3) that concealing their sexual orientation produced more negative behavior from their straight partner, with a lower bound $95 \%$ CI that slightly included zero (which could shift with higher $N$ ). However, this perception was not verified in straight participants' self-reports or judgments from independent sexual minority coders.

Straight participants could have exhibited less visible cues that were not captured by our coders when they interacted with sexual minorities who disclosed (vs. revealed) their sexual orientations, and sexual minorities who disclosed in turn perceived less discrimination. Future research could code for more subtle nonverbal behaviors but general impressions, as measured herein, are usually capable of capturing intergroup bias (Dovidio \& LaFrance, 2013).

Interestingly, scores for all three sources of perceived discriminations fell below the midpoint on 7-point scales, suggesting local norms were fairly egalitarian: Straight people did not report being prejudiced and sexual minorities (both participants and independent coders) did not perceive these straight individuals to be strongly biased as well. In fact, sexual minorities anticipated that there would be more discriminations in imagined interactions (Study $1 M=4.50$ ) compared to what they perceived in actual interactions (Study $2 M=2.51$ ). This affirms the 
notion that in egalitarian contexts, actual intergroup interactions with strangers may not be as threatening and discriminatory as one's imagination (Conley, Evett, \& Devine, 2007; Mallett, Wilson, \& Gilbert, 2008).

\section{General Discussions}

Despite rapid changes surrounding LGBTQ norms and attitudes (Tankard \& Paluck, 2017), intergroup interactions are still stressful for many sexual minorities. Even among participants who were comfortable enough to reveal their identity on a mass testing assessment and reside in a liberal university context, nearly half the participants in Study 1 chose not to disclose their sexual orientations in an imagined interaction with a straight peer. Sexual minorities may conceal their stigmatized identity to avoid potential discrimination (Crocker \& Major, 1989; Goffman, 1963). Indeed, in Study 1, the more sexual minority participants endorsed the self-protective benefits of concealment, the less likely they were to anticipate disclosing their identity. This suggests that the perceived protective benefits of concealment may lead them to approach intergroup interactions with trepidation that results in passing.

However, Study 2 suggests that disclosure does not necessarily expose sexual minorities to differential treatment when interacting with a straight peer from the same university environment. When straight participants interacted with someone whose sexual orientation was concealed (vs. revealed), they did not express less prejudice, as confirmed by their selfperception and independent sexual minority coders' perception. There was even a hint of the overcorrection hypothesis in sexual minority participants' perception, as they perceived straight participants as marginally less biased when they disclosed rather than concealed their identities. When stigmatized individuals conceal their identity, they become more pre-occupied with 
intrusive thoughts related to their stigma (Smart \& Wegner, 1999), and this may explain why sexual minorities perceived somewhat more bias when concealing (vs. disclosing) their identity.

Although concealment is adaptive in certain contexts, concealment is cognitively taxing, and leads to reduced feelings of authenticity and belongingness (Barreto \& Ellemers, 2003; Newheiser \& Barreto, 2014; Smart \& Wegner, 1999). Disclosure to healthcare providers is associated with health benefits such as higher treatment adherence and better wellbeing, likely because providers can offer more specialized services and resources (Ruben \& Fullerton, 2018). When concealing this important identity that carries certain health risks, sexual minorities are unable to access proper healthcare.

Straight participants were no less positive when interacting with sexual minorities who disclosed (vs concealed) their identity, but positivity toward the stigmatized might not be genuine, especially if the behaviors were merely satisfying social norms. The strongest manifestation of insincere positivity would be captured by the over-correction hypothesis, which was not supported in our data, but has been documented within interracial interactions when evaluative concern is salient (Mendes \& Koslov, 2013; Vorauer \& Turpie, 2004). These overcorrective behaviors are usually observable but perceived as threatening and suspicious by racial minorities (Kunstman, Tuscherer, Trawalter, \& Lloyd, 2016; Major et al., 2016; Mendes et al., 2008). Although this research has not been extended to sexual minorities, this could be a fruitful future avenue to better understand intergroup perception in an understudied population.

\section{Limitations}

This research draws strengths in considering multiple sources of perceived discrimination using self-reports from both potential targets and perpetrators of bias, as well as independent perceivers. Furthermore, the study involved the laborious process of recruiting unacquainted 
straight and sexual minorities to participate in dyadic interactions. Nevertheless, there are limitations. First, both studies were conducted on a campus in a liberal city, where sexual minorities are represented in visible leadership positions, such as university president and mayor. This context could have provided stronger normative sanctions on prejudice than other cities or universities, contributing to the support for the egalitarian norm perspective. Nonetheless, these liberal contexts have broad ecological impact because sexual minorities often relocate to such places to feel more belongingness, and these relocations can even trigger the coming-out experience (Lewis, 2012), making the context similar to the lived experiences of many sexual minorities. It remains an open question as to how these findings might change in other contexts. As bias is still visible in many parts of the US and around the world (Herek \& McLemore, 2013), concealment might be self-protective in those contexts.

Second, both studies recruited sexual minorities who were already out (or at least comfortable enough to indicate their sexual orientation in pre-screening). If we were able to recruit sexual minorities who were still in the closet, we might see even stronger predictive power for the concealment as self-protective motivation. However, assigning these individuals to reveal their sexual orientations would likely cause considerable distress.

Our experimental manipulation in Study 2 randomly assigned sexual minorities to conceal or disclose their sexual orientation rather than doing so naturally under their own volition during the interaction. This powerful method, while not naturalistic, ensured that the observed effects were due to our manipulation as opposed to certain characteristics inherent in those who are more willing to disclose their stigmatized identity when meeting someone new.

Finally, given the logistical constraints of this type of research, our studies are relatively underpowered, which requires cautious interpretation of results. All investigations involve 
methodological tradeoffs, and sample size is a tradeoff tolerated here in light of strong behavioral methods with a sample that is underrepresented in both science and society. However, statistical power does not rely solely on sample size; other methods that target effect sizes such as powerful experimental manipulations can likewise increase power (Meyvis \& Van Osselaer, 2017). For example, there is enhanced ecological validity and psychological realism in a study that randomly assigns individuals to conceal or reveal their identity in an actual interaction compared to a study in which people imagine doing so. This sense of realism can produce effects that are stronger than those from more removed, cooler imagined experiences (Conley et al., 2007; Woodzicka \& LaFrance, 2001). This experimental realism, in combination with the important psychological motives and concerns at play during intergroup interactions (Richeson \& Shelton, 2007), makes for a psychologically potent manipulation and experience for sexual minority and straight participants in Study 2.

\section{Conclusion}

Intergroup interactions are challenging and they can expose stigmatized individuals to prejudice. Consequently, individuals with concealable stigmas may try to pass as a nonstigmatized to avoid such fate. Study 1 showed that half of the sample chose to conceal their sexual orientations, and this was predicted by their belief that concealment is self-protective. Actual intergroup interactions in Study 2 did not show different behavioral treatment of sexual minorities when they concealed or revealed their identity. These studies suggest that sexual minorities may perceive concealment to be a necessary strategy even in a fairly liberal and progressive context, but this could potentially deprive them of opportunities to form meaningful connections (Newheiser \& Barreto, 2014), particularly in university settings where lifelong friendships are regularly forged and prejudice is highly regulated. Future research and policies 
should be devoted to understanding how institutions can better foster an environment of inclusivity to welcome all stigmatized identities. 


\section{References}

Barreto, M., \& Ellemers, N. (2003). The effects of being categorized: The interplay between internal and external social identities. European Review of Social Psychology, 14, 139170.

Conley, T. D., Devine, P. G., Rabow, J., Evett, S. R. (2003). Gay men and lesbians' experiences in and expectations for interactions with heterosexuals. Journal of Homosexuality, 44, 83109.

Conley, T. D., Evett, S. R., \& Devine, P. G. (2007). Attitudes, subjective experiences, and behaviors in imagined and actual encounters between gay and heterosexual people. Journal of Homosexuality, 53, 35-63.

Crandall, C. S., Eshleman, A., \& O’Brien, L. (2002). Social norms and the expression and suppression of prejudice: The struggle for internalization. Journal of Personality and Social Psychology, 82, 359-378.

Crocker, J., \& Major, B. (1989). Social stigma and self-esteem: The self-protective properties of stigma. Psychological Review, 96, 608-630.

Crocker, J., Major, B., \& Steele, C. (1998). Social stigma. In D. Gilbert, S. T. Fiske \& G. Lindzey (Eds.), Handbook of social psychology (4th ed., pp. 504-553). New York, NY: McGraw-Hill.

Dasgupta, N., \& Rivera, L. M. (2006). From autonomic antigay prejudice to behavior: The moderating role of conscious beliefs about gender and behavioral control. Journal of Personality and Social Psychology, 91, 268-280.

Dovidio, J. F., \& LaFrance, M. (2013). Race, ethnicity, and nonverbal behavior. In J. A. Hall \& M. L. Knapp (Eds.), Nonverbal communication (pp. 671-695). Berlin: deGruyter Mouton. 
Goffman, E. (1963). Stigma: Notes on the management of a spoiled identity. Englewood Cliffs, NJ: Prentice-Hall.

Griffith, K .H., \& Hebl, M. R. (2002). The disclosure dilemma for gay men and lesbians: “Coming out” at work. Journal of Applied Psychology, 87, 1191-1199.

Hebl, M. R., Foster, J. B., Mannix, L. M., \& Dovidio, J. F. (2002). Formal and interpersonal discrimination: A field study of bias toward homosexual applicants. Personality and Social Psychology Bulletin, 28, 815-825.

Herek, G. M., \& McLemore, K. A. (2013). Sexual prejudice. Annual Review of Psychology, 64, 309-333.

JASP Team (2018). JASP (Version 0.9) [Computer software].

Jones E. E., Farina A., Hastorf A. H., Markus H., Miller D. T., Scott R. A. (1984). Social stigma: The psychology of marked relationships. New York: W. H. Freeman.

Kunstman, J. W., Tuscherer, T., Trawalter, S., \& Lloyd, E. P. (2016). What lies beneath? Minority group members' suspicion of Whites' egalitarian motivation predicts responses to Whites' smiles. Personality and Social Psychology Bulletin, 42, 1193-1205.

Lewis, N. M. (2012). Remapping disclosure: Gay men's segmented journeys of moving out and coming out. Social \& Cultural Geography, 13, 211-231.

Major, B., \& Gramzow, R. H. (1999). Abortion as stigma: Cognitive and emotional implications of concealment. Journal of Personality and Social Psychology, 77, 735-745.

Major, B., Kunstman, J. W., Malta, B. D., Sawyer, P. J., Townsend, S. S. M., Mendes, W. B. (2016). Suspicion of motives predicts minorities' responses to positive feedback in interracial interactions. Journal of Experimental Social Psychology, 62, 75-88. 
Major, B., Sawyer, P. J., \& Kunstman, J. W. (2013). Minority perceptions of Whites' motives for responding without prejudice: The Perceived Internal and External Motivation to Avoid Prejudice Scales. Personality and Social Psychology Bulletin, 39, 401-414.

Mallett, R. K., Wilson, T. D., Gilbert, D. T. (2008). Expect the unexpected: Failure to anticipate similarities leads to an intergroup forecasting error. Journal of Personality and Social Psychology, 94, 265-277

Mendes, W. B., \& Koslov, K. (2013). Brittle smiles: Positive biases toward stigmatized and outgroup targets. Journal of Experimental Psychology: General, 142, 923-933.

Mendes, W. B., Major, B., McCoy, S., \& Blascovich, J. (2008). How attributional ambiguity shapes physiological and emotional responses to social rejection and acceptance. Journal of Personality and Social Psychology, 94, 278-291.

Meyvis, T., \& Van Osselaer, S. M. (2017). Increasing the Power of Your Study by Increasing the Effect Size. Journal of Consumer Research, 44, 1157-1173.

Miller, C. T., Kaiser, C. R. (2001). A theoretical perspective on coping with stigma. Journal of Social Issues, 57, 73-92.

Miller, C. T., Rothblum, E. D., Felicio, D., Brand, P. (1995). Compensating for stigma: Obese and nonobese women's reactions to being visible. Personality and Social Psychology Bulletin, 21, 1093-1106.

Murphy, N. A., Hall, J. A., Mast, M. S., Ruben, M. A., Frauendorfer, D., Blanch-Hartigan, D., ... Nguyen, L. (2015). Reliability and validity of nonverbal thin slices in social interactions. Personality and Social Psychology Bulletin, 4, 199-213. 
Newheiser, A. K., \& Barreto, M. (2014). Hidden costs of hiding stigma: Ironic interpersonal consequences of concealing a stigmatized identity in social interactions. Journal of Experimental Social Psychology, 52, 58-70.

Pachankis, J. E. (2007). The psychological implications of concealing a stigma: A cognitiveaffective-behavioral model. Psychological Bulletin, 133, 328-345.

Plant, E. A., \& Devine, P. G. (1998). Internal and external motivation to respond without prejudice. Journal of Personality and Social Psychology, 75, 811-832.

Quinn, D. M., \& Earnshaw, V. A. (2011). Understanding concealable stigmatized identities: The role of identity in psychological, physical, and behavioral outcomes. Social Issues and Policy Review, 5, 160-190.

Quinn, D. M., \& Earnshaw, V. A. (2013). Concealable stigmatized identities and psychological well-being. Social and Personality Psychology Compass, 7, 40-51.

Richeson, J. A., \& Shelton, J. N. (2003). When prejudice does not pay: Effects of interracial contact on executive function. Psychological Science, 14, 287-290.

Richeson, J. A., \& Shelton, J. N. (2007). Negotiating interracial interactions costs, consequences, and possibilities. Current Directions in Psychological Science, 16, 316-320.

Rouder, J. N., Speckman, P. L., Sun, D., Morey, R. D., \& Iverson, G. (2009). Bayesian $t$ tests for accepting and rejecting the null hypothesis. Psychonomic Bulletin \& Review, 16, 225237.

Ruben, M. A., \& Fullerton, M. (2018). Proportion of patients who disclose their sexual orientation to healthcare providers and its relationship to patient outcomes: A metaanalysis and review. Patient Education and Counseling, 101, 1549-1560. 
Smart, L., \& Wegner, D. M. (1999). Covering up what can’t be seen: Concealable stigma and mental control. Journal of Personality and Social Psychology, 77, 474-486.

Sommers, S. R., Norton, M. I. (2006). Lay theories about white racists: What constitutes racism (and what doesn't). Group Processes and Intergroup Relations, 9, 117-138.

Tankard, M. E., \& Paluck, E. L. (2017). The effect of a Supreme Court decision regarding gay marriage on social norms and personal attitudes. Psychological Science, 28, 1334-1344.

Vorauer, J. D., \& Turpie, C. A. (2004). Disruptive effects of vigilance on dominant group members' treatment of outgroup members: Choking versus shining under pressure. Journal of Personality and Social Psychology, 87, 384-399.

Westgate, E. C., Riskind, R. G., \& Nosek, B. A. (2015). Implicit preferences for straight people over lesbian women and gay men weakened from 2006 to 2013. Collabra, 1, 1-10.

Woodzicka, J. A., \& LaFrance, M. (2001). Real versus imagined gender harassment. Journal of Social Issues, 57, 15-30. 